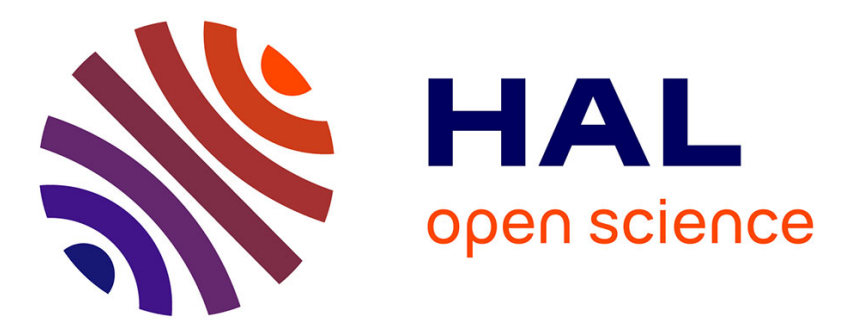

\title{
Optical and structural properties of silicon oxynitride deposited by plasma enhanced chemical vapor deposition
}

J. Dupuis, E. Fourmond, D. Ballutaud, N. Bererd, M. Lemiti

\section{To cite this version:}

J. Dupuis, E. Fourmond, D. Ballutaud, N. Bererd, M. Lemiti. Optical and structural properties of silicon oxynitride deposited by plasma enhanced chemical vapor deposition. Thin Solid Films, 2010, 519, pp.1325-1333. 10.1016/j.tsf.2010.09.036 . in2p3-00734027

\section{HAL Id: in2p3-00734027 https://hal.in2p3.fr/in2p3-00734027}

Submitted on 10 Jan 2019

HAL is a multi-disciplinary open access archive for the deposit and dissemination of scientific research documents, whether they are published or not. The documents may come from teaching and research institutions in France or abroad, or from public or private research centers.
L'archive ouverte pluridisciplinaire $\mathbf{H A L}$, est destinée au dépôt et à la diffusion de documents scientifiques de niveau recherche, publiés ou non, émanant des établissements d'enseignement et de recherche français ou étrangers, des laboratoires publics ou privés. 


\title{
Optical and structural properties of silicon oxynitride deposited by
}

\section{Plasma Enhanced Chemical Vapor Deposition for photovoltaic}

\section{applications}

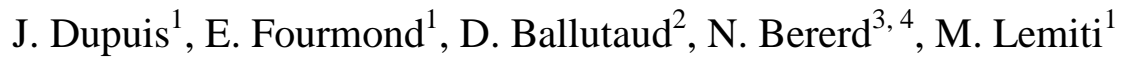

${ }^{1}$ Institut des Nanotechnologies de Lyon, UMR 5270, INSA-Lyon, 7 avenue Jean Capelle, Bât. Blaise Pascal, 69621 Villeurbanne Cedex, France

${ }^{2}$ Groupe d'Etude de la Matière Condensée, UMR 8635, CNRS, 1 place Aristide Briand, 92195 Meudon Cedex, France

${ }^{3}$ Université de Lyon, Université Claude Bernard Lyon 1(UCBL), CNRS, Institut de Physique Nucléaire de Lyon, 4 rue Enrico Fermi, Bât Paul Dirac, 69622 Villeurbanne Cedex, France

${ }^{4}$ Institut Universitaire Technologique (IUT) A de Lyon ; Département de chimie, UCBL ; 43, boulevard du 11 novembre 1918 ; 69622 Villeurbanne cedex; France
\end{abstract}

\section{ABSTRACT}

\footnotetext{
${ }^{1}$ Corresponding author. Tel.: +33-472-438-233; Fax: +33-472-738-531.

E-mail address : julien.dupuis@insa-lyon.fr (J. Dupuis)
} 
We present an overview of the properties of silicon oxynitride material ( $\mathrm{SiON}$ ) deposited by Plasma Enhanced Chemical Vapor Deposition (PECVD) for photovoltaic applications. SiON films were deposited using silane $\left(\mathrm{SiH}_{4}\right)$, ammonia $\left(\mathrm{NH}_{3}\right)$ and nitrogen protoxide $\left(\mathrm{N}_{2} \mathrm{O}\right)$ as precursor gases in a low frequency PECVD. Varying the gas flow mixture leads to a whole range of SiON layers starting from the silicon oxide to the silicon nitride with unique stoichiometries and properties. Thanks to spectroscopic ellipsometry measurements we have confirmed the suitability of $\mathrm{SiON}$ for antireflection coating layers due to the range of the refractive indexes attainable. SiON structure was analyzed by X-ray photo-electron spectroscopy. We have thus highlighted the critical role of oxygen behavior on the SiON network and the progressive replacement of nitrogen by oxygen atoms when the oxygen precursor increases. The type of chemical bonds present in SiON layers was also investigated by infrared spectroscopy. The SiON layers also contain a non-negligible amount of hydrogen which might be useful for passivation applications. The behavior of hydrogen content was thus analyzed by elastic recoil decay analysis and desorption characterization. A typical rapid thermal annealing was performed on the SiON samples in order to simulate the solar cells contact annealing and to investigate its impact on the dielectric film properties. It was found that hydrogen becomes weakly bonded to the films and strongly decreases in quantity with the annealing. The surface passivation effect is presented in the last part of this paper. The trend before and after a rapid thermal annealing showed opposite results which could be explained by the high porosity of the layers and the formation of Si-O bonds.

KEYWORDS : SiON, XPS, FTIR, ERDA, Surface passivation, Solar cells 


\section{INTRODUCTION}

Silicon nitride $(\mathrm{SiN})$ and silicon oxynitride $(\mathrm{SiON})$ are widely used in the microelectronic field as in Si-based large-scale integration circuit technology or in optoelectronic devices. In the photovoltaic field, the refractive index of the amorphous hydrogenated form of $\mathrm{SiN}\left(\mathrm{SiN}_{\mathrm{x}}: \mathrm{H}\right)$ was found to be ideal as it causes very low absorption in the solar spectrum range and excellent passivation properties on the silicon surface and within the silicon bulk in the case of multi-crystalline material [1]. For that reason, in the previous decade, silicon nitride has become a standard to realize the front antireflection coating of industrial solar cells. Plasma enhanced chemical vapor deposition process (PECVD) is currently one of the preferred deposition method for the $\mathrm{SiN}$ films due to a lower thermal budget than the other CVD processes and a high amount of hydrogen in the layer.

At the present time, the $\mathrm{SiON}$ stays a suitable material for optoelectronic devices and integrated circuits such as waveguides or thin-film transistors [2, 3, 4]. But until recently, this material was not a serious candidate to compete with SiN for photovoltaic applications.

The situation might yet change. The amorphous hydrogenated form of the SiON dielectric $\left(\mathrm{SiO}_{\mathrm{x}} \mathrm{N}_{\mathrm{y}}: \mathrm{H}\right)$ presents some similar aspects to $\mathrm{SiN}$ : it can be deposited at low temperature by PECVD, it exhibits low absorbance and an adjustable refractive index below 1.5 and up to $3.0[5,6]$ by changing the precursor gas flow ratio during the deposition process. Thus, these properties can be suitable for photovoltaic industry especially for the antireflection multi-layers coatings by adjusting carefully the optical index and the 
thickness of the film [7]. Multi antireflection layers can increase the short circuit current more than two percent for cell under air which may be used for high efficiency or specific module technology [8]. With the use of SiON, multi antireflection layer can be performed in the same reactor at relatively low temperature $\left(<400{ }^{\circ} \mathrm{C}\right)$. The passivation effect of $\mathrm{SiON}$ is also under investigation to look for an alternative to the actual aluminium back surface field, which is responsible for high constraints on the back side of the thin silicon solar cells. From this point of view, a layer of SiN can be used but its passivation effect could be limited due to its high positive fixed charge density [7]. On the other hand, stack structures consisting of $\mathrm{SiN}$ and/or silicon oxide layers (abbreviated $\mathrm{SiO}$ afterwards) are a promising way to optimize the rear surface passivation without the use of high temperature process $[9,10,11]$. Finally, the low SiON refractive index make this layer suitable to act as a rear surface reflector for infrared photons which are less absorbed in the silicon.

Although a lot of studies have been done on the SiON material deposited by PECVD, the microelectronics and photovoltaics objectives are not completely similar. For that reason, the optimization of the $\mathrm{SiON}$ films will be different in both cases.

This work aims to study the optical, structural and electrical properties of SiON deposited by PECVD on silicon substrates for solar cells applications. Firstly, the optical properties of the layers deposited in our PECVD reactor will be presented. Secondly, we will investigate the structure of these layers by X-ray photo-electron spectroscopy, Fourier transform infrared spectroscopy and elastic recoil decay analysis measurements with a special attention to the hydrogen content of our films. Finally, we will study the passivation properties using minority carrier lifetime measurements, in order to show whether the PECVD SiON is a suitable material for passivation purposes. 


\section{EXPERIMENTAL DETAILS}

SiON layers were deposited with a mixture of ammonia $\left(\mathrm{NH}_{3}\right)$, pure silane $\left(\mathrm{SiH}_{4}\right)$ and nitrous oxide $\left(\mathrm{N}_{2} \mathrm{O}\right)$ as precursor gases in a semi-industrial Low Frequency PECVD reactor (LF-PECVD). The reactor was developed by SEMCO-Engineering and presents a vertical configuration chamber (figure 1).

We chose to keep the silane gas flow constant at $25 \mathrm{sccm}$, while varying both $\mathrm{NH}_{3}$ and $\mathrm{N}_{2} \mathrm{O}$ gas flows in order to keep the total gas flow constant. Different SiON stoichiometries were obtained by varying the "Ox" ratio, defined as:

$$
O x=\frac{\mathrm{N}_{2} \mathrm{O}}{\mathrm{N}_{2} \mathrm{O}+\mathrm{NH}_{3}}
$$

The Ox ratio is also an indicator of the oxygen and nitrogen content of the SiON layers: $\mathrm{Ox}=0.00$ corresponds to a $\mathrm{SiN}$ layer deposition, whereas $\mathrm{Ox}=1.00$ gives a $\mathrm{SiO}$ layer. This ratio will be used in the following as the main indicator to identify our samples. A total of five different $\mathrm{SiON}$ layers, including a $\mathrm{SiN}$ and a $\mathrm{SiO}$ samples, were elaborated on $\langle 100\rangle$ float zone 2 inches p-type silicon wafers with both sides polished and a resistivity of 4-7 ohm.cm. The gas flows parameters for each sample are summarized in the table 1 .

A spectroscopic ellipsometer (Jobin Yvon UVISEL) was used to obtain the optical indexes of the SiON layers, using the Tauc-Lorentz model [12]. The composition and the structure of the SiON films were analyzed by XPS (X-ray Photo-electron Spectroscopy) and ERDA (Elastic Recoil Detection Analysis) characterizations. In both cases, the measurements were made deep enough in the layers to avoid carbon or oxygen outside contaminations. 
The XPS measurements were carried out in a VG Esclalab 220iXL system, with a base pressure of $5.10^{-10}$ torr, and using an AlK source $(1486.6 \mathrm{eV}) \mathrm{X}$-ray monochromatized radiation. The energy measurements were made with a Thermo Electron hemispheric analyzer in transmission mode. The spectra were obtained with a detector using six channeltrons put in series. The pass electron energy was $20 \mathrm{eV}$ with a $0.1 \mathrm{eV}$ pitch. The spectra resolution is $0.3 \mathrm{eV}$. The samples surface were etched using an Ar beam of 3 $\mathrm{keV}$ with a current density of $4 \mu \mathrm{A} / \mathrm{mm}^{2}$ applied during 1 minute. The energy levels of XPS were calibrated with Au single crystal. The spectra were processed using the VG Eclipse Datasystem. The background contribution was included in the fitting process, using the Shirley method [13].

The ERDA characterizations were performed on the $4 \mathrm{MV}$ Van de Graaff accelerator of the Nuclear Physic Institute of Lyon using 1.7 MeV kinetics energy alpha particles.

To study the hydrogen bonding environment we have used infrared transmission measurements. We have operated a Fourier-Transform infrared spectrometer (FTS60 A, BioRad Inc.) associated with a Deuterated Triglycine Sulfate detector operating in the spectrum range of 1.6 to 20 micrometers to characterize the SiON samples.

The loss of hydrogen in the SiON layers due to thermal treatment has also been investigated in more details with Temperature Programmed Desorption (TPD) measurements. The characterization process consists to put the sample under vacuum and to apply a slow temperature ramp. The quantity of hydrogen that exodiffuses from the layer under such a treatment is then measured by mass spectrometry. 
Finally, we have studied the surface passivation properties of our layers by measuring the minority carrier lifetime (MCL), using photoconductance decay (PCD) measurements by a WCT-100 Photoconductance Tool from Sinton Consulting [14]. SiON layers of $70 \mathrm{~nm}$ have been deposited on both sides of float-zone polished 1-10 ohm.cm silicon wafers, n-type and p-type ( $<100>$ oriented). The high quality of the silicon wafer implies that the effective lifetime measured depends essentially on the surfaces recombination velocity, since the bulk minority carrier lifetime is superior to 3 milliseconds in this case.

\section{OPTICAL PROPERTIES}

The refractive indexes and the thicknesses results are summarized in the table 2 . The refractive index incertitude is \pm 0.02 and the thickness $\pm 2 \%$. The values are in agreement with the literature $[15,16,17,18]$. As previously discussed [6], the absorption coefficient $\mathrm{k}$ remains lower than $10^{-3}$ for wavelengths above $300 \mathrm{~nm}$. For that reason, front solar cells applications as antireflection coatings are possible.

The increase of the Ox ratio, and consequently the $\mathrm{N}_{2} \mathrm{O}$ flow, entails lower refractive indexes. According to Mattson et al. [16], the refractive index is controlled by the oxygen specific volume, in other words by the $\mathrm{Si}-\mathrm{O}$ electron density bonds. The replacement of the nitrogen atoms by the oxygen atoms induces a slight increase of the bond angle of the $\mathrm{Si}-\mathrm{O}-\mathrm{Si}$ bridges, and results in a lesser $\mathrm{Si}-\mathrm{O}$ electron density, which decreases the refractive index. The refractive index of the $\mathrm{Ox}=1.00$ layer is still above the value observed for $\mathrm{SiO}_{2}$, since the layer has not the same stoechiometry and contains hydrogen, as it will be shown in the following. 


\section{STRUCTURAL PROPERTIES}

Most of the XPS results has been already published in a previous study [6]. In this section, we will combine the XPS and the ERDA results to establish the complete stoichiometry of the dielectrics layers.

\subsection{ATOMIC COMPOSITION}

The SiON chemical compositions are plotted on the figure 2. The incertitude was taken to $\pm 2 \%$ for the ERDA results, according to the approximate density of the layers, and to $\pm 4 \%$ for XPS results because of some variations in the composition depending on the depth of the analysis within the layer.

The main change in the composition from $\mathrm{Ox}=0$ to $\mathrm{Ox}=1$ comes from the oxygen and the nitrogen contents. As expected, a higher $\mathrm{N}_{2} \mathrm{O}$ flow during the process leads to an increase in the oxygen incorporation within the layer. Moreover the plot highlights the fact that the relative oxygen content is almost opposed to the nitrogen one, while silicon and hydrogen contents do not vary notably. This trend suggests a replacement of the nitrogen atoms by the oxygen atoms during the increase of the Ox ratio. This replacement is partly due to the higher oxygen precursor concentration during the deposition process, but also to a more thermodynamic stability of the $\mathrm{Si}-\mathrm{O}$ bond $(4.7 \mathrm{eV})$ compared to the $\mathrm{Si}-\mathrm{N}$ bond $(3.7 \mathrm{eV})$ [19]. This tendency has been previously observed for SiON layers deposited by PECVD with no ammonia in the precursor gazes [15, 20]. 
The amount of hydrogen within the layers is in accordance with other authors $[15,18]$ and does not vary significantly between the samples $(13 \%-18 \%)$, except for the $\mathrm{SiO}$ layer $(4 \%)$. This notable drop of concentration can be explained by the low hydrogen content of the precursor's gases, since no ammonia is used in that case. Naskar noticed the same phenomenon for $\mathrm{SiON}$ samples based on $\mathrm{N}_{2} \mathrm{O}$ and $\mathrm{SiH}_{4}$ when the flow of $\mathrm{SiH}_{4}$ becomes low [15].

\subsection{XPS PEAK DECOMPOSITION}

The XPS analysis does not only give the atomic composition of a material but brings also information about the bonding environments within the layer.

Although our materials are amorphous, non-stoichiometric and contain a lot of hydrogen, a microscopic order is always observed within the layer. Two models are commonly used to describe this order: the random mixture model (RMM), and the random bounding model (RBM) [21]. Both models are based on the silicon-centered tetrahedrons with in-plane triply coordinated nitrogen as bonding structures. For the RMM, the bonding structure of the SiON consists of a random mixture of silicon, nitrogen and oxygen, where stable phases like $\mathrm{Si}_{3} \mathrm{~N}_{4}$ and $\mathrm{SiO}_{2}$ prevail. In the $\mathrm{RBM}$, the structure is controlled statistically by the nearest nitrogen and oxygen atoms bonded randomly to the silicon tetrahedrons.

\subsubsection{SILICON 2p ELECTRON CONFIGURATION PEAKS}

The $2 p$ electron configuration of the silicon has been analyzed to investigate the degree of organization of the $\mathrm{SiON}$ matrix, and to study its change with the progressive replacement of nitrogen by oxygen atoms. The associated XPS peak is located near an 
electron binding energy of $100 \mathrm{eV}$. The peaks and the Gaussian fits for the five samples are presented on the figure 3 and the table 3.

A shift occurs when the oxygen concentration increases in the layer. This shift is particularly obvious when the $\mathrm{SiN}$ film and the $\mathrm{SiON}$ films are compared. Usually, a shift in the electron binding energy can be attributed to a charge transfer caused by the atoms electronegativity [22]. The electronegativities of silicon, hydrogen, nitrogen and oxygen are respectively $1.74,2.20,3.07$ and 3.50 , considering the Allred and Rochow scale [23]. Thus, the Si-O and $\mathrm{Si}-\mathrm{N}$ bonds have both a strong ionic behavior and consequently, the shift can be mainly attributed to the energy difference between these two bonds. Every peak exhibits a nearly-gaussian profile, independently of the stoichiometry. This tends to prove that the film structure is dominated by a single amorphous phase as suggested by the RBM. But the change of the full width at half maximum (FWHM) between the samples reveals some dispersions on the bond frequencies, and thus points out structural disorders and different local bonding environments [24]. This indicates that the layer could contain some local specific environments within the matrix (like for instance the silicon nanocrystals for silicon-rich $\mathrm{SiN}$ as reported by [25]), or a more various bonding environment due to oxygen incorporation.

To analyze the cause of the shift and the FWHM variation, XPS peaks are decomposed according to the reference data from [7], [21] and [22]. The table 4 presents the results of the decomposition for the five samples. The uncertainties on the peak contributions are $\pm 3 \%$. Note that we did not choose to introduce hydrogen environment in the database because it would have involved too many possible chemical species with similar electron binding energy. The hydrogen will be analyzed further by the decomposition of the XPS nitrogen 1s peak configuration. 
The decomposition of the SiN sample, presented in the figure 4, is in accordance with previous work [7]. The layer is however richer in silicon than the reference silicon nitride $\mathrm{Si}_{3} \mathrm{~N}_{4}$ (The N/Si ratio is 0.75 compared to 1.33 ). The silicon bonding environment thus reveals a high contribution of the $\mathrm{Si}-\mathrm{N}_{4}$ species $\left(\mathrm{Si}_{3} \mathrm{~N}_{4}\right)$ with a silicon-rich contribution.

Unsurprisingly, the bonding environment tends to become oxygen-rich while increasing the Ox ratio. This point is evident on the decomposition of the $\mathrm{Si}(2 \mathrm{p})$ global peak, with the disappearance of the species based on nitrogen. More interesting is the high contribution of the $\mathrm{Si}-\mathrm{O}_{4}$ species related to $\mathrm{SiO}_{2}$ right from the nitrogen-rich $\mathrm{SiON}(\mathrm{Ox}=$ $0.20)$ : nearly $40 \%$ of the peak decomposition is associated with $\mathrm{Si}^{-\mathrm{O}_{4}}$ although the layer contains only $20 \%$ of oxygen (figure 2). Besides, as suggested by the high FWHM, the bonding environment is more varied and four contributions are needed to decompose correctly the richer nitrogen $\mathrm{SiON}$ films $(\mathrm{Ox}=0.20$ and 0.58$)$ as shown in the figure 4. The contribution of the $\mathrm{Si}_{-} \mathrm{O}_{4}$ species does not vary for the three intermediate $\mathrm{SiON}$ : the decrease of the $\mathrm{Si}-\mathrm{N}_{4}$ is counter-balanced by the increase of the $\mathrm{O}_{\mathrm{x}}-\mathrm{Si}-\mathrm{N}_{\mathrm{y}}$ species.

The strong change in the matrix with the incorporation of oxygen is probably due to its high reactivity with the silicon. As it was already mentioned, this reaction is thermodynamically preferred to any others. This may explain the high contribution of the oxygen-based environment despite the relatively low oxygen content (near $20 \%$ on figure 2). The disappearance of the nitrogen environment when Ox increases is slow and follows the decrease of the atomic nitrogen contribution in the film (figure 2), as the table 4 and figure 4 tend to prove. 


\subsubsection{NITROGEN 1s ELECTRON CONFIGURATION PEAKS}

Contrary to silicon, $\mathrm{N}-\mathrm{O}$ bonds are not thermodynamically privileged compared to $\mathrm{N}-\mathrm{H}$ or N-Si (2.1 eV against 4.0 and $3.7 \mathrm{eV}$ respectively [7][19]). Thus, to analyze the hydrogen content through the study of the nitrogen peak $\mathrm{N}(1 \mathrm{~s})$ is easier than with the $\operatorname{Si}(2 p)$ peak.

Unfortunately, the nitrogen composition varies significantly with the Ox ratio and the decomposition becomes harder for the nitrogen-poor films. Thus, we have chosen to focus on the general trend of the peaks.

As for the silicon, the nitrogen peaks seem to be Gaussian (figure 3). The nitrogen environment is probably also dominated by a single amorphous phase. A shift of the N(1s) peak to higher binding energy and a variation of the FWHM are also visible (table 5). The larger FWHM obtained when the Ox ratio increases is probably caused by some more various chemical environments with the oxygen complex. The reason of the shift could be a consequence of the oxygen content increase. However, since $\mathrm{N}-\mathrm{O}$ bonding is non-thermodynamically privileged, hydrogen atoms may also play a role due to their electronegativity. This hypothesis is strengthened by the behavior observed on the $\mathrm{SiO}$ sample: a strong shift of the N(1s) peak occurs to lower energy for this layer although oxygen was present in high concentration. But contrary to the oxygen, the hydrogen concentration fall steeply between the $\mathrm{SiON}(\mathrm{Ox}=0.87)$ and the $\mathrm{SiO}$ sample. Thus, the disappearance of the hydrogen could explain the shift of the $\mathrm{N}(1 \mathrm{~s})$ peak. Note that the FWHM reduction for the $\mathrm{Ox}=1.00$ sample suggests a more uniform bonding environment, but the signal of the nitrogen peak was too noisy to analyse the $\mathrm{N}(1 \mathrm{~s})$ peak unambiguously. The decomposition of the N(1s) peaks confirms that the evolution of the matrix is driven by a progressive replacement of the nitrogen atoms by the oxygen atoms. 
Moreover, the hydrogen is probably localised preferentially near the nitrogen atoms, as suggested by the shift of the $\mathrm{N}(1 \mathrm{~s})$ peaks.

\subsection{INFRARED SPECTROSCOPY MEASUREMENTS}

In the photovoltaic field, the hydrogen content of the film is very important for the passivation point of view [26]. It is thus necessary to investigate in more details how the hydrogen is bonded within the films, and how it reacts when the layers are annealed during the metallic front contacts formation at the end of the standard solar cell fabrication process.

One set of the samples was annealed in a lamp furnace under pure air atmosphere at $800{ }^{\circ} \mathrm{C}$ during few seconds. The annealing profile is shown in the figure 5 , and is equivalent to the standard annealing process for the contact formation. The Fourier-transform infrared (FTIR) spectra obtained with these samples are shown in the figure 6. We will describe the most important regions and confront them to the XPS results. A more detailed analysis of the FTIR spectra has been already published in [6].

The predominant band between $800 \mathrm{~cm}^{-1}$ and $1200 \mathrm{~cm}^{-1}$ is mainly caused by the Si-N and the Si-O groups in the stretching mode [20][28]. The peaks localised at $1180 \mathrm{~cm}^{-1}$ and $3350 \mathrm{~cm}^{-1}$ correspond to $\mathrm{N}-\mathrm{H}$ bending and stretching vibration respectively [29]. At $2200 \mathrm{~cm}^{-1}$ stands the Si-H stretching mode and lastly, the small peak at $3500 \mathrm{~cm}^{-1}$ can be identified as the H-O-H stretching vibration [17]. Note that the $2000-4000 \mathrm{~cm}^{-1}$ spectral region was magnified five times for appreciation.

Going from the $\mathrm{SiN}$ to the $\mathrm{SiO}$ films, the main peak moves from the $\mathrm{Si}-\mathrm{N}$ stretching mode to the Si-O stretching and rocking modes as expected from the previous XPS 
analysis: the oxygen atoms take progressively the place of the nitrogen atoms and the oxygen reacts in priority with the silicon. This is confirmed by the decrease of the Si-N, $\mathrm{N}-\mathrm{H}$ and $\mathrm{Si}-\mathrm{H}$ related peaks. The presence of water is also detected through the $\mathrm{H}-\mathrm{O}-\mathrm{H}$ bond and the presence of absorption peaks in the $1400-1800 \mathrm{~cm}^{-1}$ range, despite a complete atmosphere purge in the FTIR chamber. The presence of water in $\mathrm{SiON}$ films has also been reported by Yeh and Lee [30] for oxygen-rich samples deposited at 250 ${ }^{\circ} \mathrm{C}$. The authors have suggested that the water presence was related to the decrease of the incoming rate of $\mathrm{SiH}_{\mathrm{n}}$ radicals towards the surface during the deposition. This would allow the hydrogen atoms in the plasma to remove the $\mathrm{O}-\mathrm{H}$ bonded to silicon more easily, and to form water. Nevertheless, the quantity of water remains extremely weak in our layers. Note that no water-related peak is visible for the annealed films, which confirms its formation during the layer deposition.

The hydrogen is mainly bonded to the silicon and the nitrogen for the nitrogen-rich Si$\mathrm{ON}$, and to the nitrogen for the oxygen-rich $\mathrm{SiON}$. Going from $\mathrm{SiN}$ to $\mathrm{SiO}$, the $\mathrm{Si}-\mathrm{H}$ and $\mathrm{N}-\mathrm{H}$ bonds quantity decreases slowly, until the almost disappearance of both contributions in the spectra, probably due to the formation of preferential Si-O bonds.

No noticeable change are observed in the FTIR spectrum after annealing. The N-H stretching modes decrease in intensity (figure 7), and the $\mathrm{Si}-\mathrm{H}$ stretching mode remains only slightly visible for the $\mathrm{SiN}$ and the nitrogen-rich $\mathrm{SiON}$ films. A shift of the $\mathrm{Si}-\mathrm{O}$ stretching mode to a higher wavenumber is also visible (figure 8).

Despite its rapidity, the annealing step reached $800{ }^{\circ} \mathrm{C}$ and was efficient enough to break a significant amount of the weakest bonds in the SiON films. The FTIR spectra highlight clearly a loss in bonded hydrogen within the layers after the annealing. We 
would have expected a higher decrease of the $\mathrm{Si}-\mathrm{H}$ bonds due to its relative weak energy compared to the others $(3.3 \mathrm{eV}$ against 4.0 and $3.7 \mathrm{eV}$ for $\mathrm{N}-\mathrm{H}$ and $\mathrm{Si}-\mathrm{N}$ bonds [7][17]). In practice, some authors have observed a higher breaking rate for the $\mathrm{N}-\mathrm{H}$ bonds than for the $\mathrm{Si}-\mathrm{H}$, caused by the so-called cross-linking effect [31]. It is a synergy effect between the Si-H and N-H bonds which leads to the reaction:

$$
\mathrm{Si}-\mathrm{H}+\mathrm{N}-\mathrm{H} \rightarrow \mathrm{Si}-\mathrm{N}+\mathrm{H}_{2}
$$

This effect is not always effective and depends on the layer formation conditions. In our case, the lost of $\mathrm{N}-\mathrm{H}$ and $\mathrm{Si}-\mathrm{H}$ bonds after annealing are both significant. The cross linking effect seems to play a major role for the nitrogen-rich $\mathrm{SiON}$ since more $\mathrm{Si}-\mathrm{N}$ bonds are present after the annealing (figure 8). In the oxygen-rich films, this effect is not visible since the $\mathrm{Si}-\mathrm{O}$ bonds formation is preferred and leads to a slight shift of the $\mathrm{Si}-\mathrm{O}$ stretching mode after annealing. Note that the annealing seems to affect also the Si-N bonds in oxygen-rich $\mathrm{SiON}$ as the steep fall of the peak may suggest.

The bonded hydrogen seems to decrease evenly with the Ox ratio, although the ERDA analysis points out only a slight decrease for atomic hydrogen, followed by a strong drop for the $\mathrm{SiO}$ sample. This may indicate the existence of other forms of hydrogen bonds.

\subsection{HYDROGEN CHARACTERISATION}

To investigate more precisely the various form of hydrogen in our SiON films, ERDA, Raman and Temperature Programmed Desorption (TPD) measurements were used. Both ERDA and Raman characterizations were performed on as-deposited and annealed samples. 
The figure 9 displays the atomic hydrogen content for our SiON films determined by ERDA before and after annealing. The data before annealing is the same than the one presented on the figure 2 . As assumed by the FTIR results, the annealing treatment decreases the hydrogen concentration, but not uniformly. Thus, another source of hydrogen should exist in the films. Trapped water could be a possible element but as shown in the FTIR section, the quantity seems to be too small to explain the whole change in the hydrogen content in the ERDA results. Moreover, this explanation could not work with nitrogen-rich SiON films since no water is detected. Another hypothesis is the presence of the dihydrogen molecules trapped in the SiON matrix.

\subsubsection{Raman analysis}

The Raman spectra on the figure 10 show the contribution of the $\mathrm{H}_{2}$ molecule (near $4120 \mathrm{~cm}^{-1}$ ) [32] for the four nitrogen-richest films. We note that the spectra after annealing (not presented) show no evidence of dihydrogen molecules in any sample.

Although the Raman peak proves the presence of trapped dihydrogen molecules, the signal remains too weak to bring a significant contribution to the total content of hydrogen within the layer. This is confirmed by the weak variation of the hydrogen content for the SiN layer (figure 9) despite a clear loss of dihydrogen molecules with the annealing observed on Raman spectra.

The presence of trapped dihydrogen molecules in the nitrogen-rich SiON films could be possible within denser films than the oxygen-rich layers, which could probably not keep the $\mathrm{H}_{2}$ molecules efficiently [30]. 


\subsubsection{HYDROGEN DESORPTION}

The temperature ramp used for TPD measurements is linear, with a rate of $20{ }^{\circ} \mathrm{C}$ per minute. This process is thus really different from the rapid thermal annealing profile used for solar cell contact firing.

The desorption profiles shown on figure 11 are quite different, depending on the type of SiON films. The strong signals observed at temperature higher than $750{ }^{\circ} \mathrm{C}$ are due to the destruction of the films. The SiN film begins to release hydrogen near $450{ }^{\circ} \mathrm{C}$, whereas it starts at lower temperatures for the others samples. The desorption profile is also weaker for the $\mathrm{SiO}$ film according to its low hydrogen content.

The most important point is the desorption threshold temperature localized near $200{ }^{\circ} \mathrm{C}$ for most of the SiON films, whereas all the films depositions are performed at $370{ }^{\circ} \mathrm{C}$ (figure 1). This may be explained by the rapid cooling rate of the samples at the end of the deposition process: the samples are extracted from the PECVD reactor in the ambient air when they are still hot. Thus, a rapid cooling could occur and may freeze the SiON network suddenly. Consequently, a strong disorder might exist in the network, so that a moderate temperature increase would allow the release of a part of the hydrogen trapped in the films. For the SiN film, the higher density of the layer (2.6 versus 2.3 for the $\mathrm{SiO}$ layer) could refrain the hydrogen exodiffusion at low temperature. In all cases, a portion of the hydrogen is weakly linked to the SiON films. The FTIR spectra have shown the presence of covalent hydrogen bonds like $\mathrm{N}-\mathrm{H}$ and $\mathrm{Si}-\mathrm{H}$, which are strong enough to be broken only above $400{ }^{\circ} \mathrm{C}$, as suggested by the previous results for the $\mathrm{SiN}$ sample [7][33]. The presence of dihydrogen and water in some SiON samples is thus demonstrated, but despite being good candidates to exodiffuse at low temperature, their quantities remain too small to be significant. 
Another possibility to explain the low-temperature exodiffusion of hydrogen may be the presence of hydrogen in the form of polar bond. This type of bond is essentially electrostatic, and is generally present in solution with high electronegative atoms; its energy is clearly inferior to a covalent bond [34]. The best example for these hydrogen bonds is the water where most of the individual molecules are linked to their neighbors, due to the polarity of the $\mathrm{H}_{2} \mathrm{O}$ molecule. The presence of a similar type of bond is possible in the SiON samples because the layers are rich in nitrogen and oxygen, both atoms with high electronegativity. During the annealing time shown on figure 5 , the plateau at $450{ }^{\circ} \mathrm{C}$ during 25 seconds can lead to the release of this weak-bonded hydrogen for the SiON samples. But the $\mathrm{SiN}$ and $\mathrm{SiO}$ samples are only weakly affected by this plateau because most of the hydrogen is strongly bonded $(\mathrm{SiN})$, or it is in small quantity $(\mathrm{SiO})$. The decrease in $\mathrm{H}$ content is thus more important for SiON samples (figure 9), and the release of hydrogen starts at lower temperature (figure 11). The TPD profiles differences between these three intermediate SiON samples could be attributed to their respective structural networks (see part 4.2) which might enhance the exodiffusion of the hydrogen. Finally, if a part of the hydrogen is effectively bonded to high electronegative atoms, the oxygen concentration can probably play a major role on the quantity of weak-linked hydrogen.

\section{SURFACE PASSIVATION PROPERTIES}

The investigation about the hydrogen gives information about its quantity and its chemical configuration within the layers. These parameters are known to be strongly related 
to the properties of the surface passivation layers. For example, in a silicon nitride study, Mäckel and Lüdemann [35] have considered the Si-H bonds concentration as a good indicator for the passivation quality of the layer. Surface passivation results obtained from previous work on our silicon nitride layers are detailed in [7, 33].

The evolution of the minority carriers lifetime (MCL) is presented in the figure 12 . For clarity, only the results for n-type silicon are plotted, but the trend for p-type is exactly similar, with slightly lower values due to the higher capture cross-section of electron in p-type silicon [36].

Before annealing the passivation effect decreases slowly from $\mathrm{SiN}$ to $\mathrm{SiO}$. The MCL is one order of magnitude lower for the $\mathrm{SiO}$ than for the $\mathrm{SiN}$ sample. We have mentioned that the $\mathrm{Si}-\mathrm{H}$ bond density might be considered as an indicator of the passivation quality [14]. In our case the hydrogen could be linked to the $\mathrm{P}_{\mathrm{b}}$ centers $\left(\mathrm{Si}_{3} \equiv \mathrm{Si} \cdot\right)$, which are reported to be the dominating defect in un-passivated $\mathrm{SiO}$ layer [37], and which can be well passivated by the hydrogen [38]. In this point of view, the decrease of the MCL seems to be well correlated with the decrease of the $\mathrm{Si}-\mathrm{H}$ stretching mode observed with the FTIR analysis. As we have already reported elsewhere [6], we can also expect a lower fixed charges density in $\mathrm{SiON}$ than in the $\mathrm{SiN}$ layer, due to the reduction of the $\mathrm{K}^{+}$centers concentration [1], i.e. the $\mathrm{N}_{3} \equiv \mathrm{Si}^{+}$defect, which follows the decrease of the nitrogen content. This would also induce a reduction of the surface passivation when $\mathrm{Ox}$ increases. Nevertheless, additional charges might be brought by the $\mathrm{P}_{\mathrm{ox}}$ and similar centers $\left(\mathrm{O}_{3} \equiv \mathrm{Si} \cdot, \mathrm{O}_{2} \mathrm{~N} \equiv \mathrm{Si} \cdot\right.$ and $\mathrm{ON}_{2} \equiv \mathrm{Si} \cdot$ defects $)[1]$. Although their charging states are not necessarily positives, it is known that the $\mathrm{P}_{\mathrm{ox}}$ centers bring mainly a positive contribution in the silicon thermal oxide fixed charge density. 
After annealing, the results of the passivation change deeply: the nitrogen-rich samples exhibit poor MCL and the situation is opposite for the oxygen-rich SiON. The passivation effect does not change much for the SiN film and stays quite efficient (MCL near $100 \mu \mathrm{s})$. In our previous study, the strong MCL decrease for the nitrogen-rich SiON was suspected to be caused by a lower density of the layer [6]. The strong hydrogen desorption at low temperature (figure 11) partly confirms this point. Despite the formation of Si-N bonds with the annealing (figure 8), the passivation is affected by the loss of the weakly bonded hydrogen.

For the richer oxygen films, the passivation slowly increases and becomes even similar to that of the $\mathrm{SiN}$ layer with $\mathrm{SiO}$. In these layers, the presence of a higher oxygen concentration seems to help in the creation of $\mathrm{Si}-\mathrm{O}$ bonds as suggested by the figure 8 . Moreover, the exodiffusion of hydrogen from the $\mathrm{SiO}$ layer is clearly weaker than for the other layers. These two tendencies may explain the better passivation effect obtained with the oxygen-rich layers: the loss of hydrogen is counter-balanced by the formation of Si-O bonds, which passivate the surface. Besides, since the exodiffusion of hydrogen from the layer is slower in that case, it might also participate in the passivation improvement by decreasing the $\mathrm{P}_{\mathrm{b}}$ centers concentration and the other defects at the Si$\mathrm{ON} / \mathrm{Si}$ interface.

\section{CONCLUSION}

We have contributed in the chemical and structural description of the silicon oxynitride layers deposited by plasma enhanced CVD. This films have numerous advantages for 
photovoltaic applications. Their adjustable refractive index makes them suitable for multi-layers antireflection coating, in combination with a silicon nitride layer.

The ERDA and XPS characterizations have underlined the strong influence of the oxygen on the SiON network: the favourable formation of the $\mathrm{Si}-\mathrm{O}$ bonds disturbs strongly the $\mathrm{SiON}$ matrix and a part of the hydrogen becomes weakly bonded to the layer. Thus, a rapid thermal annealing has a strong impact on the hydrogen content of the layer and may degrade the passivation properties of the films.

The differences between FTIR and ERDA measurements for the bonded hydrogen and the total hydrogen content suggest the presence of other forms of hydrogen within the SiON layers. Although dihydrogen and water have been detected in the samples, their quantities are not significant to explain the differences between the ERDA and FTIR results. Thus, it is possible that the hydrogen is linked within the layer by another type of weak chemical bonds, such as polar bonds.

Although the hydrogen does not contribute to the passivation as much as in the SiN layer due to its strong exodiffusion, the formation of $\mathrm{Si}-\mathrm{O}$ bonds for the oxygen-rich films leads to a similar surface passivation. Consequently, in addition to antireflection coatings, the PECVD SiO layer becomes a good candidate for the surface passivation of solar cells. It is already widely studied in combination with $\mathrm{SiN}$ on the rear side of thin solar cells.

\section{ACKNOWLEDGMENTS}

The authors want to thanks the Nanolyon platform staff for its technical contribution, and the National Research Agency (ANR) with the French Agency for Environment and 
Energy Management (ADEME) for their financial contributions through the national projects PHARE, REDUCOP and INFIME. 


\section{REFERENCES}

[1] A.G. Aberle, Sol. Energy Mater. Sol. Cells 65 (2001) 239.

[2] Y. Wang, X. Cheng, Z. Lin, C. Zhang, F. Zhang, Vacuum 72 (2004) 345.

[3] K. Wörhoff, A. Driessen, P.V. Lambeck, L.T.H. Hilderink, P.W.C. Linders, Th.J.A. Popma, Sens. Actuators, A 74 (1999) 9.

[4] B. Semmache, M. Lemiti, C. Chanelière, C. Dubois, A. Sibai, B. Canut, A. Laugier, Thin Solid Films 296 (1997) 32.

[5] A. del Prado, E. San Andrés, F.L. Martínez, I. Mártil, G. González-Dĺaz, W. Bohne, J. Röhrich, B. Selle, M. Fernández, Vacuum 67 (2002) 507.

[6] J. Dupuis, E. Fourmond, J-F. Lelièvre, D. Ballutaud, M. Lemiti, Thin Solid Films 516 (2008) 6954.

[7] J.F. Lelièvre, PhD Thesis, Institut des Nanotechnologies de Lyon, INSA de Lyon, France, 2007.

[8] R. Einhaus, K. Bamberg, R. de Franclieu, H. Lauvray, R. Monna (Eds.), Proceedings of the $20^{\text {th }}$ European Photovoltaic Solar Energy Conference, Barcelona, Spain, June 6-10, 2000, p.1993.

[9] J. Dupuis, E. Fourmond, O. Nichiporuk, F. Gibaja, M. Lemiti (Eds.), Proceedings of the $23^{\text {rd }}$ European Photovoltaic Solar Energy Conference, Valencia, Spain, September 1-5, 2008, p.1633.

[10] M. Hofmann, S. Kambor, C. Schmidt, D. Grambole, J. Rentsch, S. Glunz, R. Preu (Eds.), Proceedings of the $22^{\text {nd }}$ European Photovoltaic Solar Energy Conference, Milan, Italy, September 3-7, 2007, p.1030.

[11] B. Rémiat, P. Saint-Cast, F. Souche, N. Enjalbert, R. Monna (Eds.), Proceedings of the $22^{\text {nd }}$ European Photovoltaic Solar Energy Conference, Milan, Italy, September 37 , 2007, p. 1755.

[12] G.E. Jellison Jr., F.A. Modine, Appl. Phys. Lett. 69 (1996) 371.

[13] D.A. Shirley, Phys. Rev. B: Condens. Matter Mater. Phys. 5 (1972) 4709.

[14] R.Sinton, A.Cuevas, Appl. Phys. Lett. 69 (1996) 2510.

[15] S. Naskar, PhD Thesis, Case Western Reserve University, Cleveland, United States, 2006.

[16] K.E. Mattsson, J. Appl. Phys. 77 (1995) 6616.

[17] F. Ay, A. Aydinli, Optical Materials 26 (2004) 33.

[18] M. Józwik, P. Delobelle, C. Gorecki, A. Sabac, L. Nieradko, C. Meunier, F. Munnik, Thin Solid Films 468 (2004) 84.

[19] B. deB. Darwent, National Standard Reference Data Series, National Bureau of Standards, No. 31, Washington, DC, 1970.

[20] M.I. Alayo, I. Pereyra, W.L. Scopel, M.C.A. Fantini, Thin Solid Films 402 (2002) 154.

[21] P. Cova, S. Poulin, O. Grenier, R.A. Masut, J. Appl. Phys. 97 (2005) 073518. 
[22] R. Saoudi, G. Hollinger et A. Straboni, Journal de Physique III 4 (1994) 881 (in french).

[23] A.L. Allred, E.G. Rochow, J. Inorg. Nucl. Chem. 5 (1958) 264.

[24] D.V. Tsu, G. Lucovsky, M.J. Mantini, S.S. Chao, J. Vac. Sci. Technol., A 5 (1987) 1998.

[25] J.-F. Lelièvre, H. Rodriguez, E. Fourmond, S. Quoizola, J. De la Torre, A. Sibai, G. Bremond, P.-J. Ribeyron, J.-C. Loretz, D. Araujo, M. Lemiti, Phys. Status Solidi B 4 (2007) 1401.

[26] B. L. Sopori, X. Deng, J. P. Benner, Sol. Energy Mater. Sol. Cells 41/42 (1996) 159.

[27] S. Dreer, P. Wilhartitz, Pure Appl. Chem. 76 (2004) 1161.

[28] I.V. Afanasyev-Charkin, L.G. Jacobsohn, R.D. Averitt, M. Nastasi, J. Vac. Sci. Technol., A 22 (2004) 2342.

[29] E. Bustarret, M. Bensouda, M.C. Habrard, J. C. Bruyère, Phys. Rev. B: Condens. Matter Mater. Phys. 38 (1988) 8171.

[30] J. Yeh, S. Lee, J. Appl. Phys. 79 (1996) 656.

[31] C.M.M. Denisse, K.Z. Troost, F.H.P.M. Habraken, W.F. van der Weg, J. Appl. Phys. 60 (1986) 2543.

[32] H.F.W. Dekkers, G. Beaucarne, M. Hiller, H. Charifi, A. Slaoui, Appl. Phys. Lett. 89 (2006), 211914.

[33] J.-F. Lelièvre, E. Fourmond, A. Kaminski, O. Palais, D. Ballutaud and M. Lemiti, Sol. Energy Mater. Sol. Cells 354 (2009) 4341.

[34] T.W Martin, Z. S. Derewenda, Nat. Struct. Biol. 6 (1999) 403.

[35] H. Mäckel and R. Lüdemann, J. Appl. Phys. 92 (2002) 2602.

[36] R.B.M. Girisch, R.P. Mertens, R.F. De Keersmaecker, IEEE Transactions on Electron Devices 35 (1988) 203.

[37] G. Agostinelli, P. Choulat, Y. Ma and Guy Beaucarne (Eds.), $17^{\text {th }}$ NREL Workshop on Crystalline Silicon Technology, Vail, Colorado, USA, August 5-8, 2007.

[38] A. Stesmans, J. Appl. Phys. 88 (2000) 489. 


\section{LIST OF TABLES :}

Table 1: Gas precursors flow for the five samples used in this study.

Table 2: Summary of the refractive indexes and thicknesses of the five samples studied.

Table 3: Silicon $2 p$ peaks position and FWHM results for a Gaussian fit of the five samples studied.

Table 4: XPS Si2p peaks decomposition. The table gives the contribution of each species to the experimental peak with their relative FWHM. The energy position of the chemical species came from [7], [21] and [22].

Table 5: Nitrogen 1s peaks position and FWHM results for a Gaussian fit of the five samples studied. 


\section{LIST OF FIGURES :}

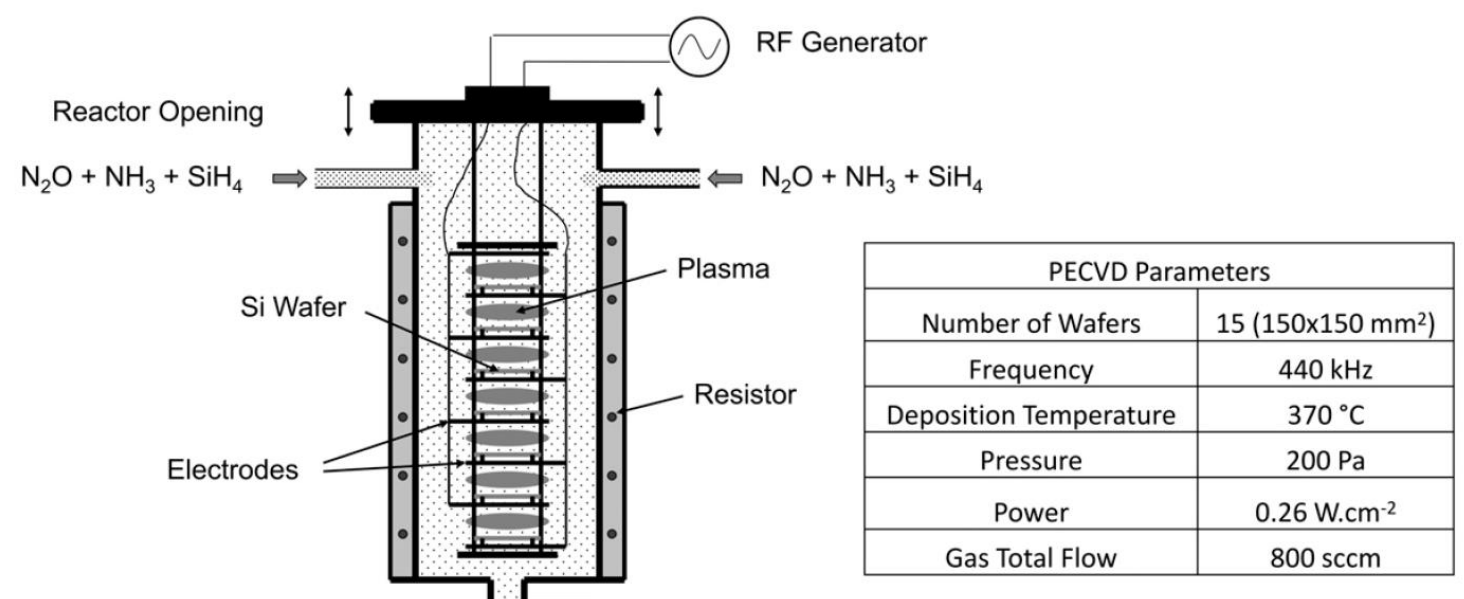

Figure 1: Diagram of the LF-PECVD reactor. The table on the right summarizes the parameters for the deposition.

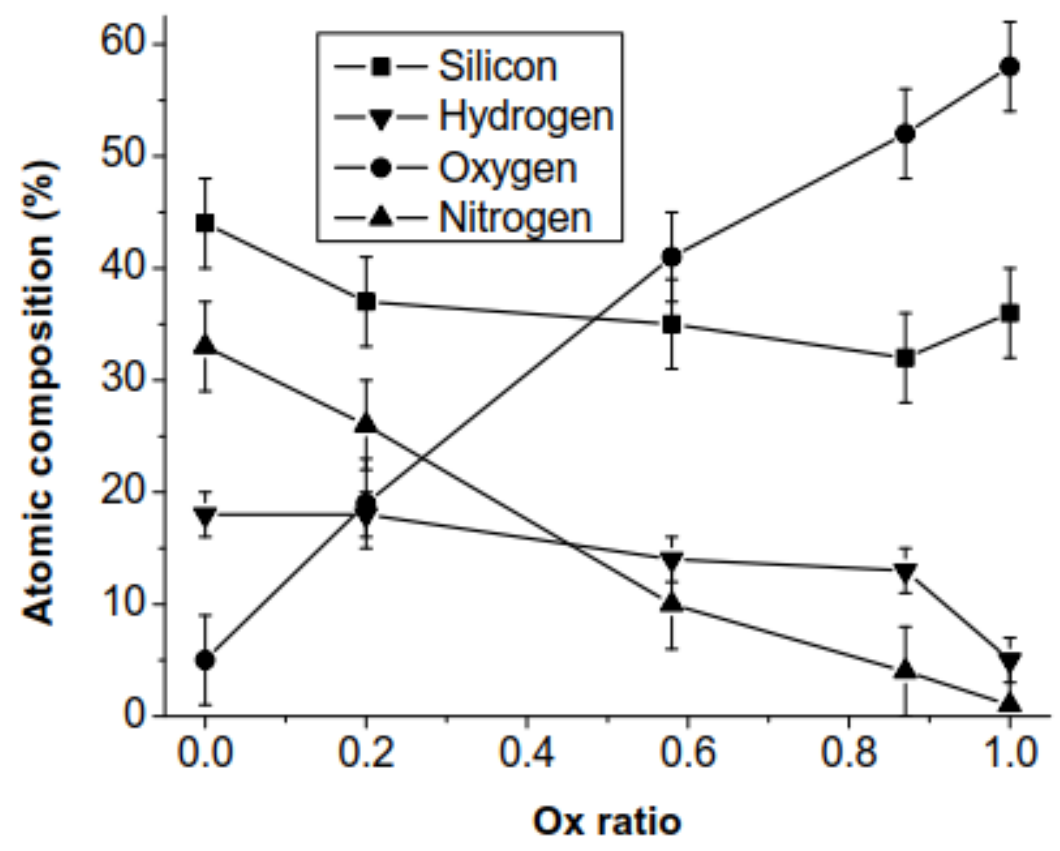

Figure 2: Atomic composition of the five studied SiON samples. Lines are guide for the eye. 

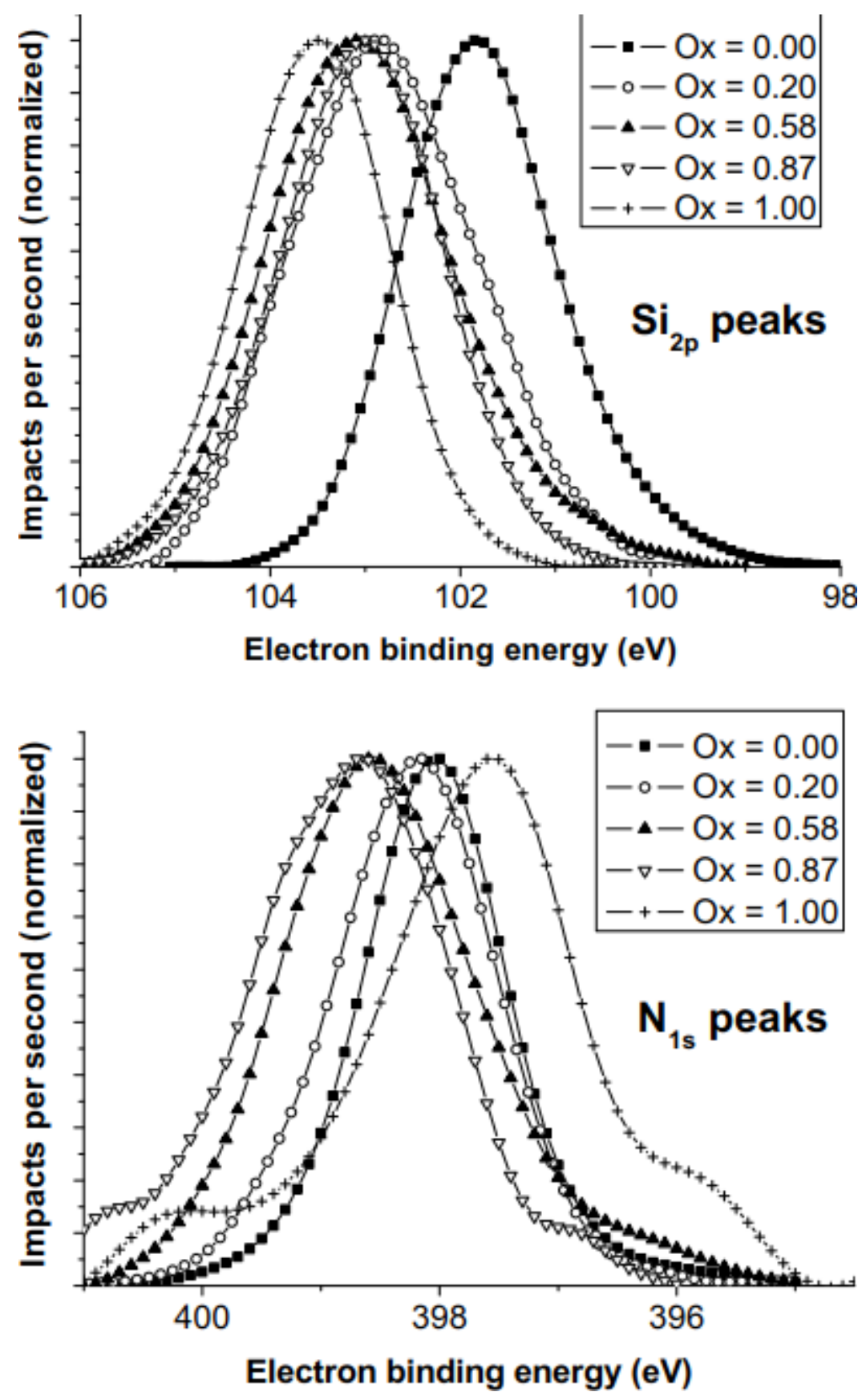

Figure 3: Normalized XPS peaks of the silicon (for the $2 p$ electron configuration) and the nitrogen (for the 1s electronic configuration) in the five SiON studied. The shoulders on the $\mathrm{SiO} N(1 \mathrm{~s})$ peak are due to the signal noise. 

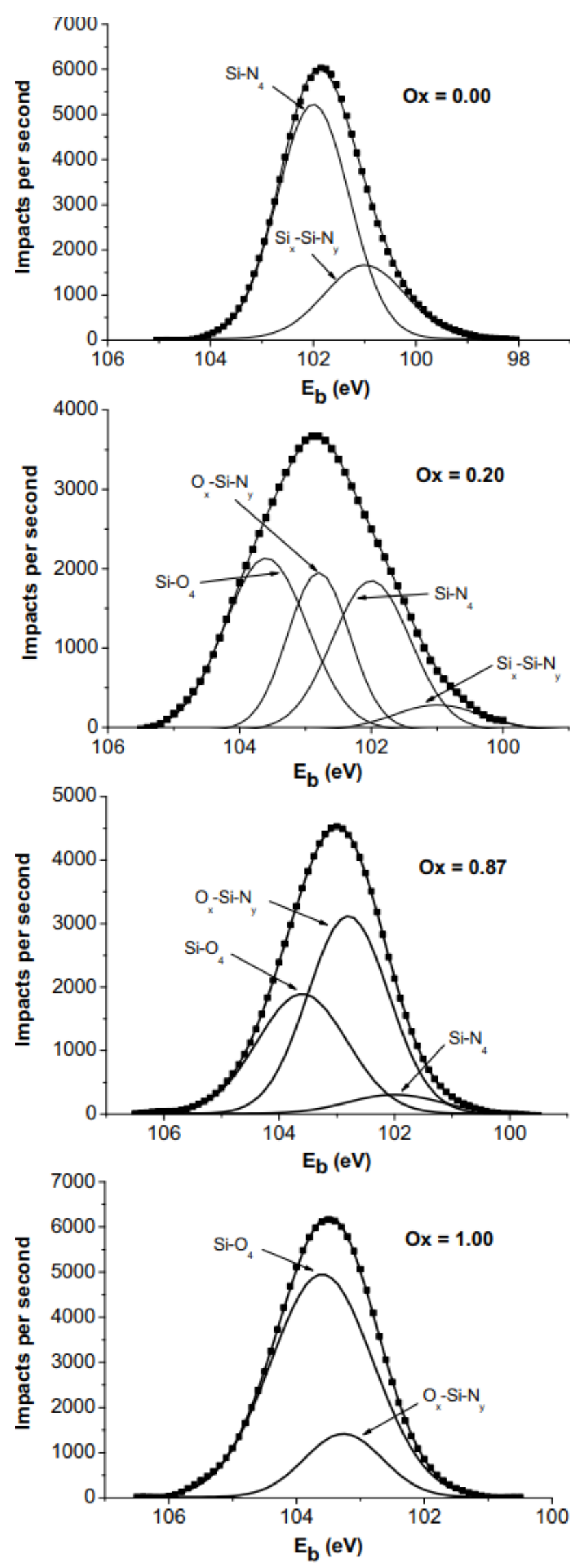

Figure 4: XPS silicon 2p peak of four SiN films. 


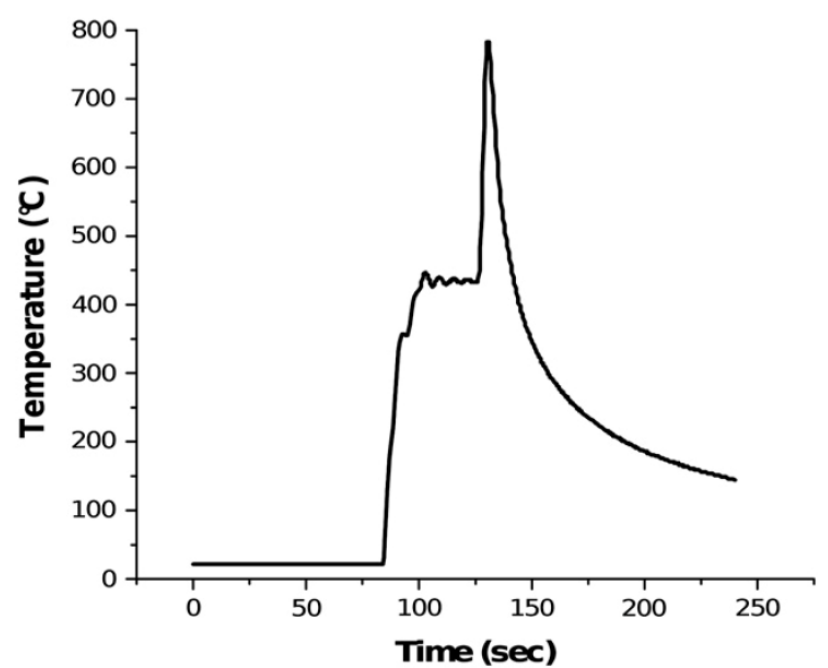

Figure 5: Temperature profile of the rapid thermal annealing step.

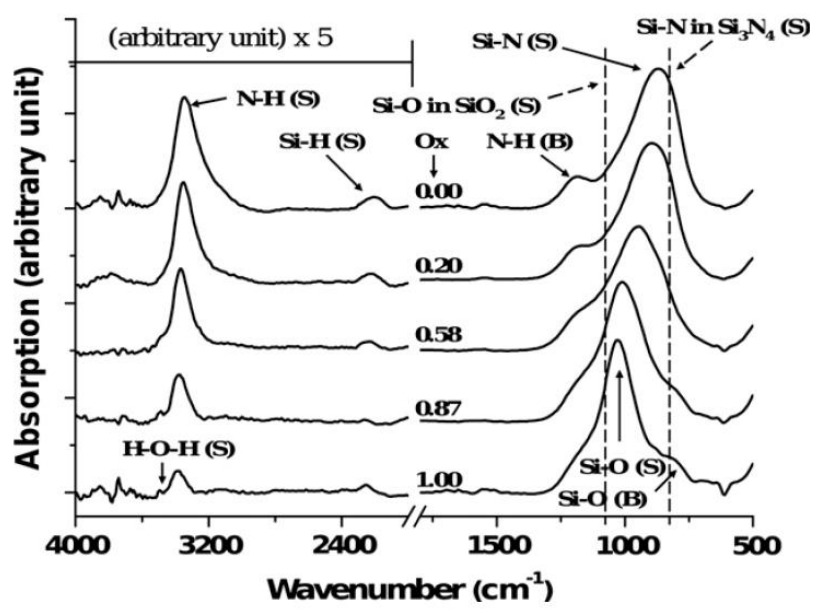

Figure 6: Thickness normalized FTIR spectra of the as-deposited SiON layers in function of the Ox ratio indicated above each spectrum. The dotted lines indicate the position of the $\mathrm{Si}-\mathrm{N}$ stretching vibration mode in $\mathrm{Si}_{3} \mathrm{~N}_{4}\left(830 \mathrm{~cm}^{-1}\right)$ and the $\mathrm{Si}-\mathrm{O}$ stretching vibration mode in thermal $\mathrm{SiO}_{2}\left(1070 \mathrm{~cm}^{-1}\right)$, respectively [27]. 


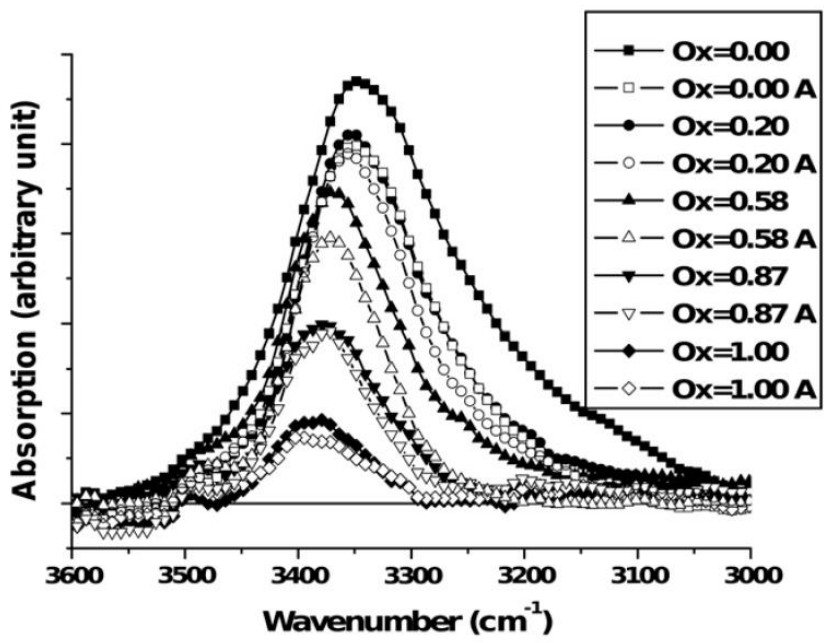

Figure 7: Zoom on the normalized FTIR N-H stretching bond spectrum. The solid and dotted lines stands for respectively un-annealed and annealed samples.

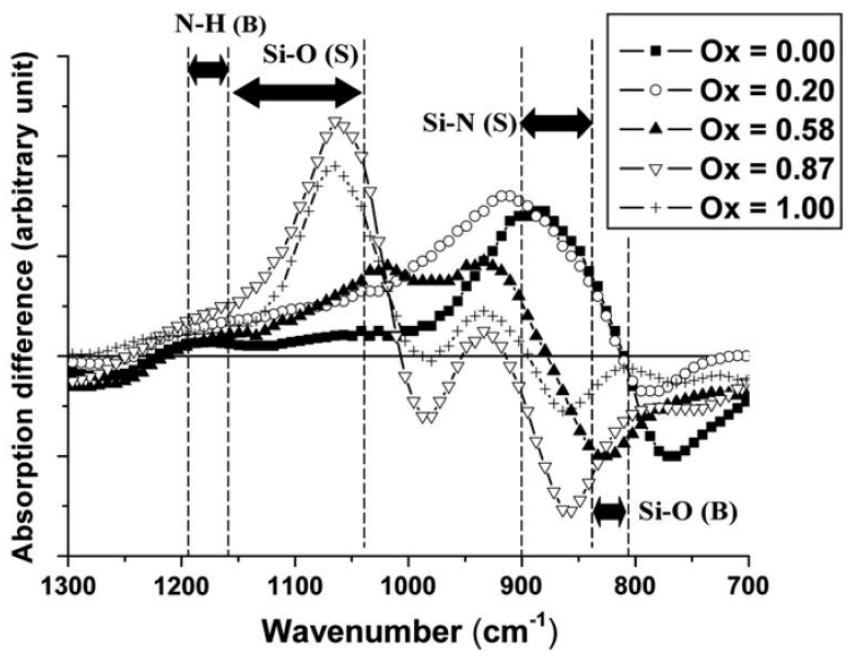

Figure 8: Subtraction of the annealed samples FTIR spectra with the un-anneal ones.

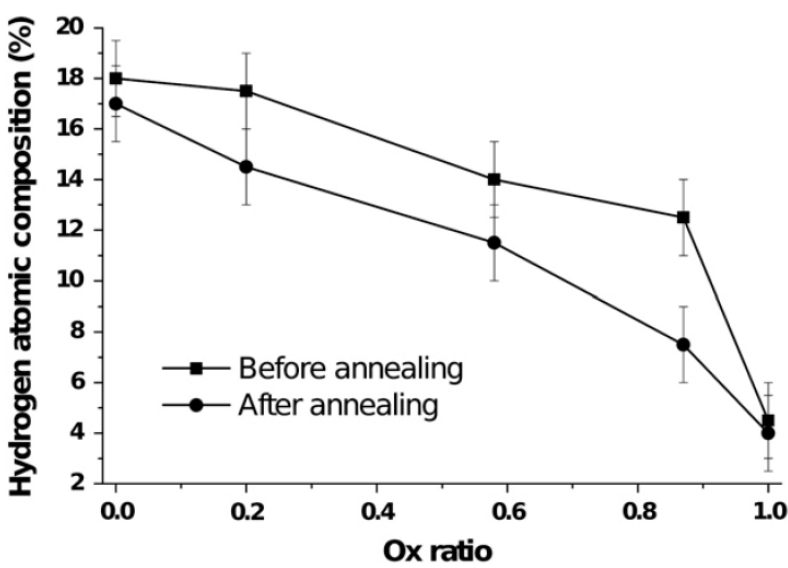

Figure 9: Evolution of the hydrogen atomic composition with the Ox ration determined by ERDA before and after annealing. Lines are guide for the eye. 


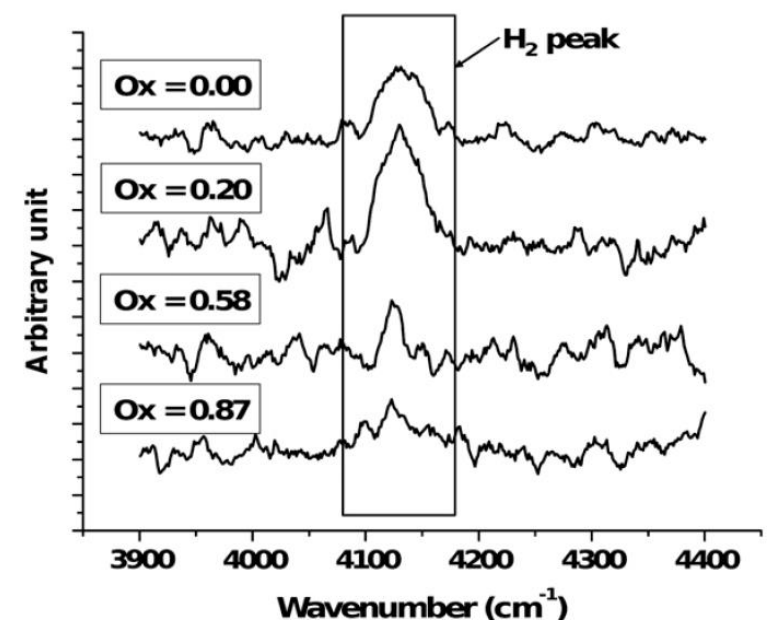

Figure 10: Raman $\mathrm{H}_{2}$ peak before annealing the $\mathrm{SiON}$ films.

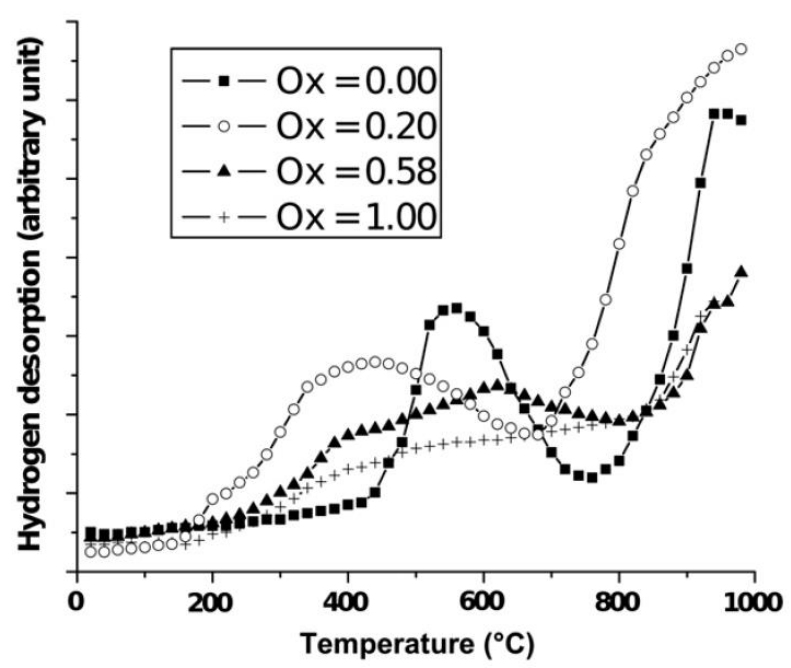

Figure 11: Hydrogen desorption profiles of the SiON films.

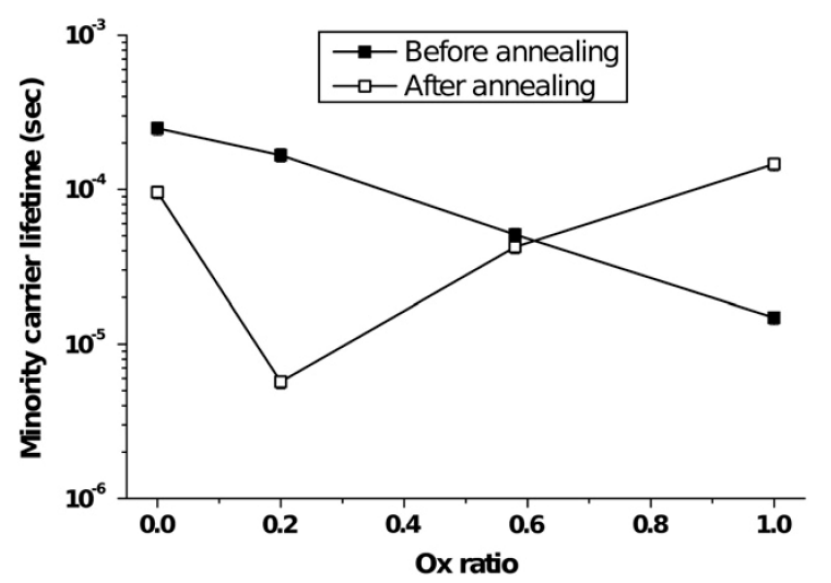

Figure 12: Evolution of minority carrier lifetime for different $\mathrm{SiN}$ and $\mathrm{SiON}$ layers according to the Ox ratio and for an excess carrier concentration of $7.10^{14} \mathrm{~cm}^{-3}$. The incertitude is near $10 \%$. 


\begin{tabular}{|c|c|c|c|}
\hline Sample & $\mathrm{SiH}_{4}$ flow (sccm) & $\mathbf{N H}_{3}$ flow (sccm) & $\mathbf{N}_{2} \mathbf{O}$ flow (sccm) \\
\hline \hline $\mathrm{Ox}=0.00$ & 25 & 775 & 0 \\
$\mathrm{Ox}=0.20$ & 25 & 620 & 155 \\
$\mathrm{Ox}=0.58$ & 25 & 323 & 452 \\
$\mathrm{Ox}=0.87$ & 25 & 100 & 675 \\
$\mathrm{Ox}=1.00$ & 25 & 0 & 775 \\
\hline
\end{tabular}

Table 1: Gas precursors flow for the five samples used in this study. 


\begin{tabular}{|c|c|c|}
\hline Sample & Refractive index at $\mathbf{6 3 3} \mathbf{~ n m}$ & Thickness $\mathbf{( n m})$ \\
\hline \hline$O x=0.00$ & 1.85 & 302 \\
$O x=0.20$ & 1.77 & 225 \\
$O x=0.58$ & 1.64 & 195 \\
$O x=0.87$ & 1.57 & 159 \\
$O x=1.00$ & 1.54 & 152 \\
\hline
\end{tabular}

Table 2: Summary of the refractive indexes and thicknesses of the five samples studied. 


\begin{tabular}{|c|c|c|}
\hline Sample & Position (eV) & FWHM (eV) \\
\hline \hline Ox $=0.00$ & 101.9 & 1.92 \\
Ox $=0.20$ & 102.9 & 2.38 \\
Ox $=0.58$ & 103.1 & 2.25 \\
Ox $=0.87$ & 103.0 & 2.01 \\
$O x=1.00$ & 103.5 & 1.82 \\
\hline
\end{tabular}

Table 3: Silicon 2p peaks position and FWHM results for a Gaussian fit of the five samples studied. 


\begin{tabular}{|c|r|r|r|c|}
\hline \multirow{2}{*}{ Sample } & \multicolumn{4}{|c|}{ Peak contribution (\%) (FWHM (eV)) } \\
\cline { 2 - 5 } & Si $_{\mathbf{x}}-\mathbf{S i}_{\mathbf{N}} \mathbf{N}_{\mathbf{y}}$ & \multicolumn{1}{|c|}{$\mathbf{S i}_{\mathbf{N}} \mathbf{N}_{\mathbf{4}}$} & $\mathbf{O}_{\mathbf{x}}-\mathbf{S i}_{\mathbf{N}} \mathbf{N}_{\mathbf{y}}$ & \multicolumn{1}{c|}{ Si-O $_{\mathbf{4}}$} \\
\hline \hline Ox $=0.00$ & $25(1.57)$ & $73(1.41)$ & - & - \\
Ox $=0.20$ & $6(1.31)$ & $32(1.18)$ & $27(0.94)$ & $39(1.26)$ \\
Ox $=0.58$ & $3(1.58)$ & $12(1.92)$ & $43(1.55)$ & $42(1.57)$ \\
Ox $=0.87$ & - & $6(1.60)$ & $56(1.40)$ & $38(1.56)$ \\
Ox $=1.00$ & - & - & $8(1.01)$ & $89(1.48)$ \\
\hline
\end{tabular}

\begin{tabular}{|c|c|}
\hline \multicolumn{2}{|c|}{ energy po } \\
\hline $\mathrm{Si}_{\mathrm{x}}-\mathrm{S}$ & \\
\hline Si-I & $: 102$ \\
\hline & . 1028 \\
\hline Si-C & $103.6 \mathrm{el}$ \\
\hline
\end{tabular}

Table 4: XPS Si2p peaks decomposition. The table gives the contribution of each species to the experimental peak with their relative FWHM. The energy position of the chemical species came from [7], [21] and [22]. 


\begin{tabular}{|c|c|c|}
\hline Sample & Position (eV) & FWHM (eV) \\
\hline \hline Ox $=0.00$ & 398.0 & 1.23 \\
Ox $=0.20$ & 398.2 & 1.40 \\
Ox $=0.58$ & 398.5 & 1.66 \\
Ox $=0.87$ & 398.8 & 1.69 \\
Ox $=1.00$ & 397.6 & 1.30 \\
\hline
\end{tabular}

Table 5: Nitrogen 1s peaks position and FWHM results for a Gaussian fit of the five samples studied. 